\title{
TINDAK PERSONA TOKOH “NDARA MAT AMIT" DAN “MBAH SIDIQ" DALAM LUKISAN KALIGRAFI KARYA A. MUSTOFA BISRI (KAJIAN PSIKOANALISIS DAN IMPLIKASINYA DALAM PENDIDIKAN MORAL ANAK)
}

\author{
PERSONA ACTSON CHARACTERS “NDARA MAT AMIT" AND “MBAH SIDIQ" \\ IN LUKISAN KALIGRAFI $B Y$ A. MUSTOFA BISRI \\ (PSYCHOANALYTIC STUDIES AND ITS IMPLICATIONS \\ IN CHILDREN'S MORAL EDUCATION)
}

\author{
Umar Sidik
}

Balai Bahasa Provinsi Daerah Istimewa Yogyakarta

Jalan I Dewa Nyoman Oka 34, Yogyakarta, Indonesia umarsidik2013@gmail.com

\begin{abstract}
(Naskah diterima tangga 23 September 2021, direvisi terakhir tanggal 11 November 2021, dan disetujui tanggal 16 November 2021)

DOI: https:/ / doi.org/10.26499/wdprw.v49i2.895
\end{abstract}

\begin{abstract}
This study aims to describe the motives of the persona of the main characters of the short stories "Ndara Mat Amit" and "Mbah Sidiq" by A. Mustofa Bisri;and what are the implications for children's moral education. The approach used in this study is the psychoanalysis of C.G. Jung, especially with regard to the act of persona. With regard to its implications in moral education, it is based on Lickona's opinion related to the importance of strategies and children's involvement in the material (reading) used. The results showed that Ndara Mat Amit acted impolite and rude persona with a motive so that his glory was not known to the public so that it could be accepted by traditional society. As a pious man who was of the Prophet Muhammad saw, he did not want to be deified, let alone cult. In addition, Ndara Mat Amit does not want to be used and co-opted by politicians who are hungry for power. Meanwhile, Mbah Sidiq acts as a pious and pious person solely to indulge worldly desires, greed. He thought that wealth would always go hand in hand with happiness and power. The implication in moral education is to discuss with children the parts where there are moral dilemmas. The teacher guides the child to be involved in the events contained in the reading. Children are asked to find answers and/or solutions to the events contained in the reading.
\end{abstract}

Keywords: psychoanalysis; persona; falsehood; moral education

Abstrak
Penelitian ini bertujuan untuk mendeskripsikan motif tindak persona tokoh utama cerpen "Ndara Mat
Amit" dan "Mbah Sidiq" karya A. Mustofa Bisri; dan bagaimana implikasinya dalam pendidikan moral
anak. Pendekatan yang digunakan dalam penelitian ini ialah psikoanalisis C.G. Jung, khususnya yang
terkait dengan tindak persona. Berkenaan dengan implikasinya dalam pendidikan moral, didasarkan
pada pendapat Lickona yang terkait dengan pentingnya strategi dan keterlibatan anak pada materi
(bacaan) yang digunakan. Hasil penelitian menunjukkan bahwa Ndara Mat Amit bertindak persona
tidak santun dan kasar dengan motif agar kemuliaan dirinya tidak diketahui masyarakat sehingga dapat
diterima oleh masyarakat tradisional. Sebagai seorang alim yang yang bertrah Nabi Muhammad saw.,
dia tidak ingin didewa-dewakan apalagi dikultuskan. Selain itu, Ndara Mat Amit tidak mau 
dimanfaatkan dan terkooptasi oleh politikus yang haus kekuasaan. Sementara itu, Mbah Sidiq bertindak persona alim dan linuwih semata-mata untuk memperturutkan syahwat keduniawian, nafsu keserakahan. Dia berpikir bahwa kekayaan akan selalu bersanding dengan kebahagiaan dan kekuasaan. Implikasi dalam pendidikan moralnya dapat dilakukan dengan mengajak anak mendiskusikan bagianbagian yang memuat dilema pesan moral. Pendidik memandu agar anak terlibat ke dalam peristiwa yang terdapat dalam bacaan. Anak diminta untuk menemukan jawaban dan/atau jalan keluar atas peristiwa yang terdapat dalam bacaan.

Kata-kata kunci: psikoanalisis; persona (topeng); kepalsuan; pendidikan moral

\section{Pendahuluan}

Persona merupakan bentuk kepribadian yang bukan sebenarnya atau wajah lain dari seseorang. Dengan kata lain, persona adalah topeng kepribadian atau sebuah karakter yang sedang diperankan (Jung, 2018: 182). Dalam Kamus Besar Bahasa Indonesia [KBBI] Daring, 2021, topeng (persona) diartikan sebagai 'sikap kepura-puraan untuk menutupi maksud yang sebenarnya'. Persona ialah "tutup raga telanjang" ego seseorang (Palmquist, 2005: 215). Topeng/persona tidak selalu bersanding dengan perbuatan negatif, tetapi dapat juga bersifat positif. Misalnya, seorang intel atau reserse bertindak persona sebagai gelandangan ketika akan menangkap penjahat. Akan tetapi, akan bermakna negatif jika ada orang yang bertindak persona sebagai ustad untuk maksud menipu orang lain. Artinya bahwa positif dan/atau negatifnya penggunaan topeng bergantung pada konteks dan tujuannya. Cerpen karya A. Mustofa Bisri berjudul "Ndara Mat Amit", dan "Mbah Sidiq" yang terdapat di dalam kumpulan cerpen berjudul Lukisan Kaligrafi (2003) menggambarkan penggunaan persona dalam pengertian tersebut.

Cerpen "Ndara Mat Amit" menampilkan sosok orang tinggi-besar, bibirnya ndower, dan tidak pernah tersenyum. Dia mempunyai kebiasaan yang aneh: mengumpat/ mencaci dengan suara keras kepada siapa saja yang ditemui (anak-anak, perempuan, laki-laki, tokoh masyarakat, kiai, dan sebagainya). Ungkapan caci-maki baginya seperti salam kehangatan saja. Jika dia datang, anakanak akan memanggilnya mat amit!, mat amit!, mat amit! (setengah mengejek) sambil berlarian karena ada perasaan takut. Kebanyakan orang merasa takut kepadanya, tetapi juga menyembunyikan hormatnya karenadesas-desus yang tersebar-dia masih keturunan Nabi. Oleh karena itu, orang-orang memanggilnya dengan sebutan Ndara Mat Amit (karena tidak tahu siapa nama yang sesungguhnya).

Pada suatu ketika Ndara Mat Amit bertandang kepada sang Kiai, tetapi anak sang Kiai itu menampakkan ketidaksukaannya kepada Ndara Mat Amit, sang Kiai pun menasihatinya:

“Ingat Cung! Penampilan orang belum tentu menggambarkan pribadinya. Bahkan, seringkali kita terkecoh jika hanya melihat dari penampilannya. Bukankah kita sering melihat orang yang tampaknya sopan dan halus, ternyata tabiatnya suka menghasut." (Bisri, 2003: 89)

Sang Kiai tampak berhati-hati menyikapi Ndara Mat Amit secara lahiriah. Ia tidak mau terjebak penampilan seseorang. Sang Kiai sadar bahwa di dunia ini banyak topeng-topeng kehidupan berkeliaran. Sangat dimungkinkan Ndara Mat Amit sedang menggunakan topeng untuk sesuatu maksud yang belum dapat diketahui oleh kebanyakan orang. Jika benar dia sebagai ulama dan keturunan Nabi, mungkin juga Ndara Mat Amit sedang menjalankan misi sucinya. 
Sementara itu cerpen berjudul "Mbah Sidiq" menampilkan sosok alim dan linuwih (sakti). Seorang tokoh yang dipercaya mempunyai ilmu makrifat yang kapasitasnya melebihi kiai mana pun. Dia dipercaya bisa berkomunikasi dengan para wali/sunan, seperti berdiskusi dengan Sunan Ampel dan Syeikh Abdul Qodir Jailani untuk memecahkan berbagai persoalan kehidupan. Tokoh fenomenal itu bernama Mbah Sidiq, seorang yang mampu menyanding empat orang istri.

Banyak orang gedhe datang dari Jakarta yang sowan ke Mbah Sidiq, mulai dari konglomerat, pejabat, politisi, artis, hingga jenderal. Mereka minta bantuan kepada Mbah Sidiq untuk membantu memecahkan masalah yang tidak terselesaikan dengan kemampuan otaknya. Salah satu pengikut setia Mbah Sidiq adalah Nasrul. Bahkan, Nasrul mempunyai andil yang sangat besar dalammembesarkan nama Mbah Sidiq dengan ke sana ke mari bercerita tentang kehebatannya.

Namun demikian, ada juga orang-orang yang menyangsikan kehebatan Mbah Sidiq. Mereka bersikap kritis, tidak mau terjebak pada cerita dan hal-hal yang bersifat indrawi semata. Mereka mempunyai alasan bahwa saat ini tindak persona (hipokrisi) telah terjadi di mana-mana yang telah menyesatkan banyak orang.

Pada dasarnya persona diperlukan dalam kehidupan untuk menjaga bagian "lunak" karakter seseorang agar aman terhadap invasi dari luar. Persona berfungsi sebagai pelindung diri supaya tidak berhadapan langsung dengan realitas dunia luar yang kejam. Oleh karena itu, persona dapat menjadi tutup pelindung agar perkembangan pribadi manusia dapat maju dengan aman (Palmquist, 2005: 212).

Tindak persona Ndara Mat Amit dan Mbah Sidiq berimplikasi atau menyugestikan dalam pendidikan moral anak. Sifat anak akan cenderung meniru hal yang bersifat heroisme (keberanian dalam menentang arus); belum terlalu kritis untuk membedakan mana yang bertentangan dengan norma dan mana yang tidak. Lickona (2013: 26) menyebutnya sebagai karakter yang berada dalam dilema moral.

Ketika anak dengan kepribadian yang dimilikinya merasa terhambat untuk melakukan sesuatu, dia berpikir manggunakan topeng agar mempermudah pencapaian tujuan yang ingin diperoleh. Topeng yang "dipakai" dapat berwujud perbuatan, tingkah laku, perkataan (bahasa), dan/atau penampilan. Tindak persona (topeng) merupakan sarana untuk memperlancar memperoleh sesuatu agar sesuai dengan harapannya.

Rokhmansyah (2018: 225) menyatakan bahwa topeng merupakan bentuk kompromi dari tuntutan lingkungan dan kepentingan diri seseorang. Topeng kadang diperlukan untuk mengatasi pergolakan kehidupan. Topeng dapat membantu untuk menyesuaikan diri dengan lingkungannya. Rahmawati (2018: 14) dalam penelitiannya menunjukkan bahwa ada seorang tokoh selalu bersepeda ketika beraktivitas ke kampus supaya dapat diakui dan berterima oleh masyarakat sebagai orang yang peduli terhadap lingkungan. Dalam kasus lain dapat kita saksikan ada orang yang menggunakan topeng (misalnya: gelar keagamaan, titel akademis, gelar kebangsawanan, pakaian, bahasa, tingkah laku, dsb) untuk mengelabui orang lain sehingga akan mudah diterima dan/atau mendapatkan simpati atau pengakuan sehingga mempermudah dalam meraih apa yang diinginkan.

Di dalam penelitian Khair (2020: 56-57) terhadap novel Lail wa Qudbhan Karya Najib Al-Kailani ditunjukkan adanya pemakaian topeng kehidupan untuk mencapai hajat yang diinginkan. Disebutkan bahwa sang narapidana (Faris) selalu menampakkan wajah tegar dan senyumannya, padahal sejatinya kepedihan dan tangisan yang ia alami. Hal itu ia lakukan agar dia dianggap menjadi 
orang kuat oleh orang-orang di sekelilingnya. Seorang istri (Inayah) berpura-pura bahagia di lingkungannya, padahal penderitaan yang ia rasakan setiap hari di dalam rumah tangganya. Dengan berat hati ia melakukan itu agar aib di dalam rumah tangganya tidak diketahui orang lain. Kejadian seperti itu bukan hanya terjadi dalam dunia cerita, tetapi banyak dapat ditemukan dalam kehidupan nyata.

Fenomena seperti itu yang digambarkan oleh A. Mustofa Bisri alam cerpennya yang berjudul "Ndara Mat Amit" dan "Mbah Sidiq" yang dibukukan dalam kumpulan cerpennya berjudul Lukisan Kaligrafi (2003). Sebagai seorang kiai, ulama, mubalig, dan ilmuwan, A. Mustofa Bisri menampilkan cerita-cerita yang lebih banyak mengangkat persoalan moralitas keagamaan. Demikian halnya dengan kedua cerpen ituyang memuat pesan (ajaran) moral (keislaman) yang dalam dan mendasar, tetapi juga kompleks.

Kumpulan cerpen karya Mustofa Bisri itu direkomendasikan untuk media (bacaan) pendidikan siswa. Rekomendasi itu tertuang dalam Surat Keputusan Badan Standar Nasional Pendidikan (BSNP), Nomor 0307/ SKEP/BSNP/V/2019, tentang Karya Sastra Indonesia Unggulan untuk Pendidikan Dasar dan Menengah (SMP/MTs, 2019). Dengan rekomendasi itu, sangat dimungkinkan bahwa karya itu banyak dibaca oleh khalayak, khususnya para pelajar.

Ndara Mat Amit dan Mbah Sidiq samasama bertindak pesona atau menggunakan topeng dalam perilaku kesehariannya. Ndara Mat Amit bertopeng dengan perilaku buruk, kasar, dan tidak menyenangkan, sedangkan Mbah Sidiq bertopeng dengan kesantunan, berperilaku baik, dan alim. Penggunaan topeng pada kedua tokoh itu tentu ada maksud dan tujuan yang ingin dicapai.

Persoalannya ialah motif apa yang menyebabkan tindak persona pada tokoh utama kedua cerpen itu? Bagaimana implikasinya dalam pendidikan moral anak? Terkait dengan itu, penelitian ini bertujuan untuk mendeskripsikan motif tindak persona tokoh utama cerpen "Ndara Mat Amit" dan "Mbah Sidiq" karya A. Mustofa Bisri; dan bagaimana implaksinya dalam pendidikan moral anak.

Permasalahan tersebut akan dijelaskan dengan perspektif psikoanalisis yang dikemukakan oleh Jung (2018: 182), khususnya yang terkait dengan tindak persona. Dikatakan oleh Jung bahwa persona (topeng) digunakan oleh seseorang sebagai tanggapan atas tuntutan-tuntutan kebiasaan dan tradisi masyarakat. Tujuan tindak persona ialah untuk menciptakan kesan tertentu kepada orang lain dan/atau untuk menyembunyikan kepribadian yang sesungguhnya.

Berkenaan dengan hal itu, Palmquist (2005: 210) menyatakan bahwa dalam interaksi sosial sering diperlihatkan kepada orang lain citra diri (tindak persona) yang berbeda dengan egonya (gambaran-diri bawah sadar manusia). Misalnya, seorang dosen akan memperlihatkan citra yang berbeda ketika di hadapan mahasiswa, ketika di lingkungan keluarganya, atau ketika bersama-sama dengan teman sekerjanya. Tindak persona akan berjalan menyesuaikan dengan situasi dan kondisi sosial masyarakat dan kepentingan yang ingin diraih.

Meskipun persona merupakan sisi penting dalam diri seseorang, tetapi hendaknya tidak dicampuradukkan pada bagian yang ditampilkan di depan publik. Jika persona lekat dengan diri seseorang, akan terbangun ketidaksadaran individualitas dan akan kehilangan sentuhan hati nurani (inner self) sehingga terjebak pada realisasi diri semata (Fiest, 2017: 117).

Terkait dengan implikasinya dalam pendidikan moral, Lickona (2013: 257) menyatakan bahwa materi yang baik saja belum cukup. Setiap materi membutuhkan strategi 
dan siasat membelajarkan kepada anak, apalagi materi moralitas yang kompleks seperti yang terdapat pada sosok Ndara Mat Amit dan Mbah Sidiq. Pendidik dituntut untuk dapat menstimulasi dan menyugesti dengan berbagai strategi agar peserta didik terlibat dan memikirkan materi yang disuguhkan.

\section{Metode}

Jenis penelitian ini ialah deskripstif kualitatif. Data penelitian bersumber dari dua cerpen "Ndara Mat Amit" dan "Mbah Sidiq" karya A. Mustofa Bisri yang terdapat dalam kumpulan cerpennya berjudul Lukisan Kaligrafi, diterbitkan oleh Penerbit Buku Kompas (2003). Kedua cerpen akan dikaji dengan pendekatan psikoanalisis Carl Gustav Jung, khususnya yang terkait dengan tindak persona. Berdasarkan kajian psikoanalisis itu, kemudian disintesiskan ke dalam pendidikan moral anak. Pengimplikasian dalam pendidikan moral anak didasarkan pada pendapat Lickona (2013: 259) tentang pentingnya pendidik pandai dalam membuat anak lebih peka terhadap pesan-pesan moral yang terdapat di dalam bacaan.

Pengumpulan data dilakukan dengan teknik simak, baca, dan catat/rekam. Data penelitian berwujud teks verbal, yang berupa frasa, klausa, dan/atau kalimat/paragraf. Adapun keabsahan data dilakukan dengan teknik validitas semantik dan pengacuan pada referensi-referensi yang relevan agar diperoleh data yang sahih. Data yang terkumpul diidentifikasi, dimaknai, dan dianalisis dengan perspektif psikoanalisis (persona). Pembahasan dilanjutkan dengan pendeskripsian dan verifikasi untuk memperoleh inferensi sesuai dengan tujuan penelitian.

\section{Hasil dan Pembahasan}

\subsection{Hasil Penelitian}

Hasil penelitian menunjukkan bahwa Ndara Mat Amit dan Mbah Sidiq dua tokoh dengan tindak persona dengan modus dan tujuan yang berbeda. Ndara Mat Amit adalah seorang ulama bertrah Nabi Muhammad dengan tindak persona menjadi gembel, urakan, dan kasar. Tujuannya ialah agar dapat diterima oleh masyarakat awam dan tidak didekati atau dimanfaatkan oleh penguasa/politikus. Sementara itu, Mbah Sidiq ialah seorang penipu bertindak pesona sebagai ulama linuwih (sakti). Mbah Sidiq selalu melakukan pencitraan diri agar memperoleh kepercayaan dari masyarakat. Tujuannya ialah memperoleh materi untuk keuntungan pribadi.

Kedua tokoh itu dapat dideskripsikan dalam tabel sebagai berikut.

Tabel 1

Deskripsi Tokoh

\begin{tabular}{|c|c|c|c|}
\hline Tokoh & $\begin{array}{l}\text { Kepriba- } \\
\text { dian Asli }\end{array}$ & $\begin{array}{c}\text { Topeng } \\
\text { yang Dipa- } \\
\text { kai } \\
\end{array}$ & Tujuan \\
\hline $\begin{array}{l}\text { Ndara } \\
\text { Mat } \\
\text { Amit }\end{array}$ & $\begin{array}{l}\text { alim, saleh, } \\
\text { terhormat, } \\
\text { trah Nabi } \\
\text { Muham- } \\
\text { mad SAW }\end{array}$ & $\begin{array}{l}\text { umpatan, } \\
\text { caci maki, } \\
\text { kata-kata } \\
\text { kasar, suara } \\
\text { keras, pa- } \\
\text { kaian kumal }\end{array}$ & $\begin{array}{l}\text { diterima } \\
\text { masyara- } \\
\text { kat } \\
\text { awam } \\
\text { dan tidak } \\
\text { terkoopta } \\
\text { si oleh } \\
\text { pengua- } \\
\text { sa. }\end{array}$ \\
\hline $\begin{array}{l}\text { Mbah } \\
\text { Sidiq }\end{array}$ & $\begin{array}{l}\text { culas, pe- } \\
\text { nipu, mu- } \\
\text { nafik }\end{array}$ & $\begin{array}{l}\text { bertingkah } \\
\text { alim, linuwih } \\
\text { (sakti); bisa } \\
\text { berkomuni- } \\
\text { kasi dengan } \\
\text { arwah para } \\
\text { wali (sunan); } \\
\text { bisa jumatan } \\
\text { ke } \\
\text { Makkah/Ma } \\
\text { dinah dalam } \\
\text { dalam } \\
\text { hitungan } \\
\text { jam }\end{array}$ & $\begin{array}{l}\text { menipu, } \\
\text { mem- } \\
\text { peroleh } \\
\text { materi } \\
\text { untuk } \\
\text { keun- } \\
\text { tungan } \\
\text { pribadi }\end{array}$ \\
\hline
\end{tabular}




\subsection{Pembahasan}

\subsubsection{Dibalik Topeng Ndara Mat Amit}

Mempunyai banyak ilmu (alim), berstatus sosial tinggi, dan bertrah terhormat lazimnya menjadi suatu kebanggaan bagi kebanyakan orang. Dengan berstatus seperti itu akan memudahkan bagi siapa pun dalam meraih keuntungan untuk kenikmatan duniawi. Namun, tidak demikian bagi Ndara Mat Amit; ia memilih menyembunyikan dirinya (menutupi identitasnya) dan menjauh dari kehidupan duniawi yang glamour. Menurut Bisri (2003: 92--93), orang seperti Ndara Mat Amit merupakan sosok yang tidak mau kehilangan lezatnya berasyik-maksyuk dengan Sang Maha Penyayang.

Ndara Mat Amit adalah manusia yang selalu takut hatinya terjangkit penyakit ujub, ria (pamer), atau sombong (Bisri, 2003: 92-93). Oleh karena itu, Ndara Mat Amit-nama aslinya Sayyid Muhammad Hamid--rela berlaku kasar, kurang santun, dan berpenampilan kumal, meskipun harus dicibirkan banyak orang. Namun, dia tetap menjaga agar hatinya tetap bersih dan tulus.

Ndara Mat Amit tidak mau terjebak dalam urusan keduniawian dan takut terkooptasi oleh penguasa demi kepentingan pragmatis. Ia tidak memedulikan penilaian masyarakat terhadap dirinya karena dia sadar bahwa dunia hanyalah sekadar permainan dan tipu daya semata.

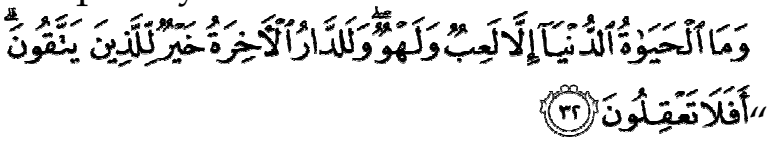

Dan kehidupan dunia ini hanyalah permainan dan senda gurau, sedangkan negeri akhirat itu, sungguh lebih baik bagi orang-orang yang bertakwa. Tidakkah kamu mengerti?" (Al-Qur'an dan Terjemahnya, Surat AlAn'am, Ayat 32; lihat juga Al-Ankabut, Ayat 64; Muhammad, Ayat 36; Thoha, Ayat 131; Fathir, Ayat 5).

Omongan kasar, tidak santun, dan penampilan kumal merupakan persona Ndara
Mat Amit untuk menutupi kealiman dan nasab kenabiannya agar tidak dikenali orang. Menurut Fitri (2015: 105) hal itu sebagai back stage dalam dramaturgi, yaitu suatu tindakan yang sengaja agar sesuatu hal yang diinginkan oleh aktor (Ndara Mat Amit) tidak diketahui oleh khalayak. Oleh karena itu, Ndara Mat Amit berperilaku seperti orang yang sangat awan, bahkan terkesan bodoh dan urakan.

Ndara Mat Amit menempuh laku yang lebih mementingkan jalan batinnya dan mengabaikan hal-hal yang kasat mata. Hal itu didasarkan pada pemahaman bahwa pada umumnya formal agama hanya menghukumi sesuatu yang kasat mata, sedangkan jalan orang sufi mengukur perilaku seseorang lebih pada sisi batinnya, tidak hanya berdasarkan yang tampak (Saliyo, 2018: 5).

Pada suatu ketika anak sang Kiai dipanggil (tepatnya dibentak) oleh Ndara Mat Amit hingga gemetaran.

"Hei, kamu, bajingan, kemari!"

“... Setan kecil! Punya telinga tidak?"

"Aku memanggilmu, Bahlul!" (Bisri, 2003: 89)

Ketika anak kecil itu mendekat dengan ketakutan dan penuh kewaspadaan, Ndara Mat Amit merogoh saku jaketnya yang kumal, seraya berkata:

"Ini, buat jajan kamu dan kawankawan!" (dengan suara yang kasar)

"Goblok! Terima!"

“... Lo, apa lagi? Kurang!?” (Bisri, 2003: 89)

Ndara Mat Mit merogoh sakunya lagi dan menambahkan uang kepada anak sang Kiai, seraya berkata

"Sekarang sana minggat!"

"Cepet minggat! Monyet kecil!!!" (Bisri, 2003: 89)

Persoalan-persoalan seperti itu yang tampaknya relatif sulit untuk dipahami bagi anak SMP/MTs dalam konteks moralitas. Mereka diajari bagaimana harus bersikap lemah- 
lembut dengan perkataan yang merendah, lembut, dan tidak boleh kasar kepada sesama (Q.S. Luqman: 19; Albaqarah: 83; Ali Imran: 159). Mereka belum mengenal jalan sufi yang seolah-olah memperbolehkan tindakan yang berbeda dengan kaidah moralitas pada umumnya.

Berkaitan dengan hal yang dilakukan oleh Ndara Mat Amit, menurut Palmquist (2005: 212) bahwa kulit-kulit persona (topeng) berfungsi tidak hanya dapat melindungi ego, tetapi juga memproteksi seluruh apa saja yang ada di alam bawah-sadar pribadinya. Hal itu ia lakukan supaya tidak berhadapan langsung dengan realitas dunia yang kejam. Kulit-persona pada perilaku Ndara Mat Amit dapat memberikan tutup yang dapat melindungi diri sehingga perkembangan kepribadiannya dapat berjalan dengan aman.

Namun demikian, sebagai hamba sejati dan ketulusan cintanya kepada Rasulullah SAW, Ndara Mat Amit tidak mampu menghindar dari panggilan hatinya. Sangat sulit bagi Ndara Mat Amit untuk menutupi kepribadian asli dengan persona-persona yang biasa ia lakukan. Ndara Mat Amit harus bersikap tawaduk dan tunduk kepada Sang Pencipta dan Rasul-Nya. Oleh karena itu, setiap kali pondok pesantren milik sang Kiai (ayah dari anak kecil yang dibentak-bentak) menyelenggaran barzanjenan dalam rangka peringatan Maulid Nabi Muhammad SAW, Ndara Mat Amit tidak pernah absen. Bahkan, dia selalu datang awal dengan pakaian kebesarannya: sarung plekat, jas berkantong besar, peci torbus merah, dan sepatu dengan kaos kaki tebal. Ndara Mat Amit terlihat paling bersemangat dalam menyahuti syairsyair yang dilagukan meskipun dengan suara sumbang dan sember. Meskipun ditertawai oleh anak-anak, Ndara Mat Amit tetap bergeming dan tidak mengurangi antusiasnya dalam barzanjen hingga paripurna.

\subsubsection{Topeng Ndara Mat Amit Tersingkap}

Pada kesempatan lain Ndara Mat Amit menghadiri lagi acara barzanjen di pondok sang Kiai dan ditemani oleh Kang Min, kusir dokar sang Kiai. Tatkala berzanjen berakhir, tidak dinyana-nyana bahwa Kang Min membuka topeng yang dikenakan oleh Ndara Mat Amit.

Awal peristiwa terbukanya topeng Ndara Mat Amit terjadi ketika hadirin barzanjen membacakan Thala'al badru 'alaina ... Ndara Mat Amit dan Kang Min sama-sama merunduk dan menangis meraung-raung sehingga menarik perhatian seluruh yang hadir, termasuk sang Kiai. Oleh karena itu, ketika acara sudah selesai, sang Kiai bertanya kepada Kang Min (kusir dokarnya):

"Kang Min, tadi waktu asyraqalan kamu menunduk dan menangis, mengapa?"

"Lho, apa Kiai tidak pirso tadi itu Kanjeng Nabi rawuh?" kata Kang Min kepada sang Kiai.

"Lho masa iya Kang Min?" sang Kiai tampak kaget. "Aku kok nggak lihat." (Bisri, 2003: 91)

Tiba-tiba Ndara Mat Amit menyahut dengan suara kerasnya:

"Kusir samber gelap!, begitu saja ente pamer-pamerkan, Min Min!, dasar kusir kucing kurap!" ....

"Kusir tengik, tak tahu malu!" (Bisri, 2003: 91)

Namun demikian, dengan beraninya Kang Min menjawab sehingga membuat banyak orang tercengang.

"Kau ini, Yik, yang tak tahu malu! dari dulu nggak capek-capeknya pakai topeng monyet. Sudahlah yang wajarwajar saja! Untuk apa pakai topeng segala? Ente pikir, dengan pakai topeng monyet, ente bisa menyembunyikan diri? Kusir dokar saja tahu siapa ente sebenarnya?" (Bisri, 2003: 91-92)

Banyak orang mengira akan terjadi huruhara dengan kejadian itu. Akan tetapi, justru 
Ndara Mat Amit merunduk dan kemudian mengucapkan salam kepada hadirin: Assalamu'alaikum .... seraya bergegas meninggalkan majelis itu entah ke mana.

Kepergian Ndara Mat Amit meninggalkan teka-teki bagi hadirin majelis barzanjen. Penyelidikan pun dilakukan dan menghasilkan temuan bahwa nama sesungguhnya Ndara Mat Amit ialah Sayyid Muhammad Hamid, sedangkan Kang Min (sang kusir dokar) bernama asli Kiai Mukmin. Keduanya merupakan orang alim dan saleh yang masih trah Nabi Muhammad saw.

Kedua orang alim itu memakai topeng, menyembunyikan dirinya agar tidak diketahui khalayak tentang kapasitas pribadinya. Keduanya ingin tampak awam, bahkan hina di hadapan umum. Sayyid Muhammad Hamid berlagak kasar yang tidak tahu sopan santun, sedangkan Kiai Hamid bersembunyi dalam pekerjaannya sebagai kusir dokar.

\subsubsection{Dibalik Topeng Kesalehan Mbah Sidiq}

Jika Ndara Mat Amit bertindak persona dengan merendahkan dirinya supaya tidak ketahuan kehebatannya oleh masyarakat umum, sebaliknya Mbah Sidiq bertindak sebagai orang alim, sakti, dan pinter; sosok mahahebat, mempunyai ilmu makrifat yang kealimannya melebihi dari kiai mana pun.

Selain bernama lazimnya seorang yang alim (Mbah Sidiq), dia juga bertindak persona dapat berkomunikasi dengan para ulama (wali) yang sudah meninggal, seperti dengan Sunan Ampel dan Syeikh Abdul Qodir Jailani. Mbah Sidiq pun seolah dapat selalu melaksanakan salat Jumat ke Makkah dan/atau Madinah walaupun bertempat tinggal di Indonesia dengan tenggat waktu yang singkat, seperti lazimnya orang Jumatan di lingkungan tempat tinggalnya.

Untuk menyempurnakan tindak personnya, ketika di makam Sunan Ampel, Mbah Sidiq melakukan dramaturgi dengan maksud ingin menjelaskan kepada khalayak (lewat pengikutnya: Nasrul) bahwa dirinya sangat istimewa. Dirinya benar-benar seorang yang memiliki kapasitas linuwih atau orang mahahebat, bahkan memiliki karamah.

Dengan disaksikan oleh Nasrul, Mbah Sidiq melakukan dialog dengan arwah Sunan Ampel. Akan tetapi, Nasrul tidak dapat mendengar dengan jelas, apa yang sedang didialogkan. Hanya ada satu kalimat yang diperdengarkan oleh Mbah Sidiq kepada Nasrul ialah "Eyang harus menolong mereka."

Beberapa saat kemudian, ketika hendak meninggalkan makam, Mbah Sidiq berkata kepada Nasrul:

"Sudah beres sekarang!"

"Orang-orang itu suka berbuat seenaknya sendiri; nanti kalau ada masalah, awak pula yang disuruh memecahkan. Dasar politisi." (Bisri, 2003: 96)

Hal yang dilakukan oleh Mbah Sidiq menurut Fitri (2015: 104) disebut sebagai manner, yaitu pertunjukan kehebatan diri kepada orang lain tentang suatu jenis peran yang oleh aktor diharapkan dapat dimainkan dalam situasi tertentu. Mbah Sidiq (aktor) membangun citra diri sebagai orang hebat di hadapan khalayak. Rokhmawan (2019: 12) menyatakan bahwa pencitraan diperlukan untuk mendapatkan pengakuan dan menarik simpati sehingga masyarakat menaruh hormat dan taat padanya. Citra diri seseorang bernilai strategis untuk melancarkan jalan menuju keinginan yang hendak diraihnya.

Nasrul yang sudah termakan pencitraan, oleh Mbah Sidiq diperankan sebagai agen untuk menyampaikan kepada masyarakat tentang kehebatan dirinya. Alhasil, skenario Mbah Sidiq berjalan dengan baik. Ketika di warung Wak Rukiban sedang banyak dikunjungi orang, Nasrul bercerita tentang kehebatan Mbah Sidiq. Nasrul membuat testemoni bahwadirinya menyaksikan Mbah Sidiq dapat berkomunikasi dengan Sunan Ampel. 
Orang-orang yang mendengarkan cerita Nasrul di warung itu tampak antusias.Mas Slamet, salah satu yang ada di warung itu, penasaran sehingga bertanya, "Siapa Srul politisi yang dibicarakan Mbah Sidiq?"

"Persisnya saya tak tahu. Soalnya banyak orang gedhe dari Jakarta yang sowan ke Mbah. Mulai dari pengusaha, artis, anggota DPR, jenderal, hingga menteri. Saya tahu di antara orang yang sowan ke Mbah itu muncul di TV." (Bisri, 2003: 96) Tatkala orang-orang di warung itu tampak mulai meyakini cerita Nasrul, tiba-tiba Haji Kusen nyeletuk: "Srul, katanya Mbah Sidiq tidak pernah salat Jumat!"

Nasrul dengan sedikit bernada emosi menjawab:

"Lho, Mbah Sidiq kan tidak seperti kita.

Mbah kalau Jumatan di Mekkah. Sampeyan tidak pernah dengar cerita Haji Narto yang bertemu Mbah di Pasar Seng Mekkah? Padahal, tahun itu Mbah Sidiq tidak naik haji. Tanyakan kepada isteriisteri Mbah yang selalu menerima oleholeh dari beliau! Kadang-kadang Mbah mengoleh-olehi mereka kalung; kadang akik fairuz; kadang kurma Medinah. Pokoknya Mbah selalu membawa buah tangan dari tanah suci untuk isteriisterinya. Padahal, setahu orang-orang, Mbah tidak ke mana-mana." (Bisri, 2003: 97)

Karena Nasrul sudah yakin bahwa Mbah Sidiq adalah seorang kiai yang sakti (linuwih), dia tidak segan-segan bercerita kepada banyak orang lebih dari sekadar apa yang dilihatnya. Nasrul ingin meyakinkan kepada khalayak bahwa Mbah Sidiq bukan hanya sekadar kiai, tetapi sepadan dengan seorang wali.

Ketika Pak Manaf menyangsikan ceritanya, Nasrul benar-benar marah.

"Beliau itu setiap hari ketemuan dengan Syeikh Abdul Qodir Jailani. Jangan sembarangan kau! Kualat baru tahu! Saya menyaksikan sendiri bagaimana Mbah berdebat dengan kiai, dengan dosen, dengan orang-orang pinter; semuanya tidak berkutik di hadapan Mbah." (Bisri, 2003: 98)

Tindak persona yang dilakukan oleh Mbah Sidiq tidak lain sebagai tanggapan atas kebiasaan dan tradisi, yaitu masyarakat mistis (Jung, 2018: 182). Oleh karena itu, banyak kasus serupa dengan yang dilakukan oleh Mbah Sidiq, misalnya Dimas Kanjeng Taat Pribadi (Probolinggo, Jatim), Tarekat Tajul Khalwatiyah Syekh Yusuf (Gowa, Sulawesi Selatan), Kerajaan Ubur-Ubur (Serang, Banten), Abdul Muhjib asal Tegal Waru, Karawang, Jawa Barat yang mengaku sebagai nabi, dan sebagainya. Mereka semua menggunakan pendekatan mistis untuk memperoleh kepercayaan dan pengakuan dari masyarakat sehingga modus operandinya lancar.

Dachrud (2015: 39) menyatakan bahwa ketika seseorang menyadari bahwa dirinya terdapat kelemahan, dia akan melakukan pemertahanan diri. Indentifikasi merupakan sebuah bentuk pertahanan diri dengan cara "memasukkan" orang lain ke dalam kepribadiannya dan membuatnya bagian dari diri sendiri. Mbah Sidiq "memasukkan" orang linuwih (semisal wali) ke dalam dirinya. Seolah-olah Mbah Sidiq dapat melakukan seperti yang dilakukan oleh para wali. Pemertahanan diri bentuk ini berfungsi untuk menghilangkan kekhawatirannya dengan cara melakukan perilaku yang mendukung penekanan kecemasannya. Seperti yang dikatakan oleh Fiest (2017: 117) bahwa Mbah Sidiq telah kehilangan sentuhan hati nurani(inner self) dan terjebak pada realisasi diri semata.

\subsubsection{Topeng Mbah Sidiq Lepas}

Dengan topengnya, Mbah Sidiq menjalankan aksinya mengelabuhi banyak orang. Sementara itu, beberapa bulan terakhir ini Nasrul 
tidak kelihatan batang hidungnya. Banyak orang bertanya-tanya ke mana Nasrul? Banyak dugaan bahwa Nasrul sedang mendampingi Mbah Sidiq menjalani aktivitasnya di luar kota. Ketika sedang menjadi rerasanan banyak orang, tiba-tiba Nasrul datang di Warung Wak Rukiban seraya menghempaskan diri di kursi dengan lesu dan wajah pucat. Setelah meneguk kopi dan mengisap rokok kreteknya, terdengar suara tajam dari mulut Nasrul: "Sidiq bajingan!"; “Wali apa macam itu."; "Bangsat, penipu!" (Bisri, 2003: 100).

Kesangsian sebagian orang bahwa Mbah Sidiq bukan orang alim dan tidak linuwih terbukti. Mbah Sidiq hanyalah penjahat yang sedang mengenakan topeng wali untuk melancarkan hasrat nafsunya. Menurut Anwar (2017: 262) kasus penggunaan agama (Islam) untuk formalitas dan sebagai topeng untuk tindak kejahatan sangat banyak terjadi. Mereka memakai topeng agama untuk mendapat keuntungan atau meraih kepentingan pribadinya, seperti yang dilakukan oleh Mbah Sidiq. Dengan topeng yang dikenakannya, Mbah Sidiq mampu menggaet banyak korban, termasuk Nasrul sendiri (orang yang turut membesakan nama Mbah Sidiq). Ironinya, kejadian pada Nasrul sangat tragis. Selain harta bendanya ludes, isteri Nasrul pun dibawa kabur oleh Mbah Sidiq.

Mbah Sidiq ialah contoh dari orang yang mempertuhkan nafsu keserakahannya. Demi hasrat nafsunya, Mbah Sidiq mengorbankan moralitas sosial dan agama. Dia menganggap bahwa keduniaan (banyaknya meteri) akan dapat membahagiakan dan memuaskan kehidupannya.

Sehubungan dengan itu, Rasulullah SAW mengingatkan kepada kita bahwa orang yang sudah memiliki keserakahan hidup tidak akan pernah merasa puas. Bahkan, dahaga yang akan terus menyertai dirinya.

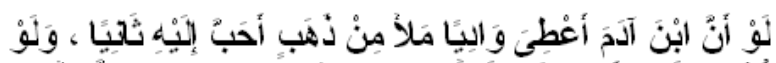

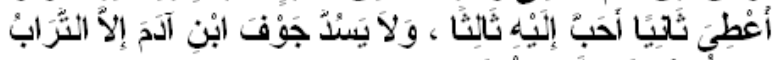

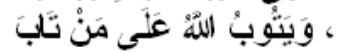

"Seandainya manusia diberi lembah penuh dengan emas, ia masih menginginkan lembah yang kedua semisal itu. Jika diberi lembah kedua, ia pun masih menginginkan lembah ketiga. Perut manusia tidaklah akan penuh, kecuali dengan tanah. Allah tentu menerima taubat bagi siapa saja yang bertaubat." (H.R. Bukhari No. 6438)

\section{Implikasinya dalam Pendidikan Moral}

Sesuai dengan Keputusan BSNP, Nomor 0307/SKEP/BSNP/V/2019 bahwa cerpen "Ndara Mat Amit" dan "Mbah Sidiq" merupakan salah satu karya sastra yang wajib untuk pendidikan dasar dan menengah. Artinya bahwa kedua cerpen itu diperuntukkan menjadi media pendidikan bagi anak-anak SMP/MTs. Hal itu sesuai dengan fungsi karya sastra, selain sebagai bacaan hiburan, juga berfungsi mengedukasi dan menyampaikan nilai-nilai pendidikan (moral).

Selaras dengan itu, Nurzakiyah (2018: 29) menyatakan bahwa nilai-nilai moral pada anak dapat ditanamkan dan dikuatkan dengan bacaan (karya sastra). Hasil penelitian Najichah, dkk. (2018: 64) juga menunjukkan bahwa karya fiksi sangat diperlukan sebagai media pendidikan moral bagi anak tingkat SMP/MTs. Namun demikian, tidak semua fiksi dapat digunakan dengan serta merta. Hal yang perlu dipertimbangkan, misalnya isi pesan moralnya, pendekatannya, penyajiannya, dan pembaca (pengguna) sasaran yang dituju oleh bacaan itu. Oleh karena itu, pengkajian, evaluasi, dan seleksi bahan bacaan menjadi sangat penting.

Nilai moral yang terdapat dalam cerpen "Ndara Mat Amit" ialah untuk menyugesti dan memotivasi kepada pembacanya (siswa $\mathrm{SMP} / \mathrm{MTs}$ ) agar jangan mudah terjebak pada kesombongan dan egoisme. Meskipun mempunyai harkat martabat tinggi, ilmu yang 
mumpuni, dan harta yang berlimpah, tidak ada alasan untuk menyombongkan diri. Ndara Mat Amit telah dijadikan model simbolik (simbolic model) dalam menyikapi eksistensi dirinya.

Yang perlu diedukasikan, disuburkan, dan disugestikan dalam diri anak-anak dengan tokoh Ndara Mat Amit ialah ketulusan hati, kerendahan hati, dan harmonisasi kehidupan. Lickona (2013: 97) menyatakan bahwa kerendahan hati merupakan kebaikan moral dan keterbukaan terhadap kebenaran. Kerendahan hati merupakan pelindung yang terbaik terhadap perbuatan jahat. Sementara itu, kebanggaan diri merupakan sumber kesombongan, arogansi, prasangka buruk, dan meremehkan orang lain. Hal itu yang diedukasikan cerpen Ndara Mat Amit kepada pembacanya.

Namun demikian, ada hal yang paradoksal dalam penokohan Ndara Mat Amit dengan pesan yang disampaikan, yaitu pada perilaku lahiriahnya. Ada kesan seolah-olah diperbolehkan berperilaku tidak sopan dan omongan kasar asal maksud dan tujuannya baik. Terdapat dilema karakter/moralitas. Sementara itu, pemahaman pada umumnya ialah tujuan yang baik harus dilakukan dengan jalan kebaikan, betapa pun hambatan yang menghadang. Oleh karena itu, perilaku tokoh (Ndara Mat Amit) akan menjadi permasalahan tersendiri dalam mengedukasi-kan ajaran moral kepada anak. Seharusnya ada keselarasan antara pengetahuan moral, perasaan moral, dan tindakan moral (Lickona (2013: 100). Siswa SMP/MTs diedukasi dalam sikap santun kepada siapa pun dan bertutur kata yang baik sebagai wujud dari pengetahuan moral.

Sementara itu, cerpen "Mbah Sidiq" bermuatan pesan tentang sifat dan perilaku moral yang seharusnya dihindari oleh anak, yaitu sifat culas, penipu, dan munafik. Sifatsifat yang harus diproteksikan kepada anak karena bertentangan dengan norma sosial dan agama. Yang disugestikan kepada anak ialah akibat buruk yang diterima dari perbuatan tercela.

Cerpen "Mbah Sidiq" diramu dengan kacamata (sudut pandang) orang dewasa. Peristiwa dan/atau problematik yang diangkat dalam cerpen itu lekat dengan urusan orang dewasa, seperti politik, ekonomi, jabatan, dan bahkan tentang seks (poligami). Latar cerita pun tentang sosial budaya-mistis yang lazimnya berurusan dengan orang dewasa.

Menurut Lickona (2013: 100), yang perlu dikembangkan dalam moralitas anak ialah kebiasaan-kebiasaan baik, contoh tindakan dan praktik menjadi orang baik, tidak bertentangan dengan konvensi sosial. Tindakan moral yang dijadikan percontoh merupakan manifestasi yang sesuai dengan pengetahuan moral anak. Dengan demikian, nilai-nilai moral yang dirasakan dan dipahami oleh anak menjadi realitas yang hidup. Salah satu prinsip belajar anak ialah learning to be (belajar untuk menjadi ...).

Sebagaimana dinyatakan oleh Laela (2015: 35), pendidikan moral untuk anak dapat dilakukan dengan dua metode, yaitu dengan pembiasaan merespons (conditioning) dan peniruan (imitation). Anak atau siswa akan lebih mudah menginternalisasi nilai moral ke dalam dirinya dengan cara meniru tokoh cerita. Oleh karena itu, tokoh-tokoh yang bermoral baik akan lebih menyugesti dalam pendidikan moral bagi anak.

\section{Simpulan}

Topeng digunakan untuk menghindari benturan dengan dunia luar yang akan menghambat keinginannya. Oleh karena itu, Ndara Mat Amit berpersona tidak santun dan kasar dengan motif supaya kemuliaan dirinya tidak diketahui masyarakat. Dia ingin diterima dan bagian dari lapisan masyarakat tradisional. 
Sebagai seorang alim yang yang bertrah Nabi Muhammad saw., dia tidak ingin didewa-dewakan apalagi dikultuskan. Selain itu, sebagai seorang yang berstatus sosial sangat tinggi, Ndara Mat Amit tidak mau dimanfaatkan dan terkooptasi oleh politikus yang haus kekuasaan.

Sementara itu, Mbah Sidiq dengan bertin-dak persona alim dan linuwih sematamata untuk memperturutkan syahwat duniawi, nafsu keserakahan. Yang terpatri dalam benak pikirannya hanyalah meraih materi sebanyak-banyaknya demi kesenangan semu. Meskipun berisiko sangat besar terhadap keselamatan dirinya, Mbah Sidiq selalu mengelabui khalayak dengan berbagai cara.

Sehubungan dengan itu, materi yang terdapat dalam kedua cerpen itu perlu dielaborasi dan kolaborasi dengan anak agar tidak disahpahami. Salah satu implikasi dalam pendidikan moral anak ialah peserta didik dituntut untuk mendiskusikan pada bagian-bagian yang terdapat dilema moral. Dengan dipandu oleh pendidik, anak dilibatkan ke dalam peristiwa yang terdapat dalam bacaan. Anak diminta untuk menemukan jawaban dan/atau jalan keluar atas kasus yang terlihat paradoksal dalam bacaan.

\section{Daftar Pustaka}

Al-Qur'an dan Terjemahnya. (n.d.). Diterbitkan oleh Sygma Creative Media Group.

Anwar, S. (2017). “Kejahatan Bertopeng Agama: Sebuah Tinjauan Sosiologi Agama." Jurnal Tarbawy: Jurnal Pendidikan Islam, Volume 4, 252-263. https:/ / doi.org/10.32923/tarbawy.v4i2. 822

Badan Standar Nasional Pendidikan (BSNP), Nomor 0307/SKEP/BSNP/V/2019, tentang Karya Sastra Indonesia Unggulan untuk Pendidikan Dasar dan Menengah, 1 (2019).
Bisri, A. M. (2003). Lukisan Kaligrafi. Kompas.

Dachrud, M. dan A. S. (2015). “Memahami Pencitraan Politik Melalui Pendekatan Mekanisme Pertahanan Diri." Potret Pemikian, Vol.19, No, 28-41. http:/ /journal.iainmanado.ac.id/index.php/PP/article/vi ewFile/730/585, diakses 17 Juli 2020.

Fiest, J. et al. (2017). Teori Kepribadian=Theories of Personality. Terjemahan. (J. at al Fiest (Ed.); VIII). Salemba Humanika.

Fitri, A. (2015). "Dramaturgi: Pencitraan Prabowo Subianto di Media Sosial Twitter Menjelang Pemilihan Presiden 2014." Jurnal Interaksi, Vol. 4, No, 101108.

https:/ / ejournal.undip.ac.id/index.php /interaksi/article/view/9740/7808, diunduh 17 Juli 2020.

Jung, C. G. (2018). Diri yang Tak Ditemukan=The Undiscovered Self (Terjemahan). IRCiSoD.

Kamus Besar Bahasa Indonesia (KBBI daring). (2020).

https://kbbi.kemdikbud.go.id/entri/to peng, diakses 20 Juli 2020.

Khair, R. (2020). “Arketipe Ketaksadaran Tokoh Faris dan Inayah dalam Novel Lail wa Qudbhan Karya Najib AlKailani." Arabiyatuna: Jurnal Bahasa Arab, Vol. 4, No, 49-67. https:/ / doi.org/10.29240/jba.v4i1.1359

Laela, Q. N. (2015). "Pemikiran Pendidikan Moral Albert Bandura." Modeling: Jurnal Program Studi PGMI, Vol. III, 21-36. http:/ / www.jurnal.stitnualhikmah.ac.id /index.php/modeling/article/view/45 /45, diunduh 18 Juni 2021. 
Lickona, T. (2013). Educating for Character $=$ Mendidik untuk Membentuk Karakter. Terjemahan Juma Abdu Wamaungo. Bumi Aksara.

Najichah, A. F. dkk. (2018). "Persepsi Pendidik dan Peserta Didik terhadap Pengembangan Buku Bacaan Cerita Fantasi Bermuatan Nilai Moral bagi Peserta Didik SMP Kelas VII." Jurnal Pendidikan Bahasa Dan Sastra Indonesia, Volume 3, 58-65.

https://doi.org/10.26737/jp-bsi.v3i2.723

Nurzakiyah, C. (2018). "Literasi Agama Sebagai Alternatif Pendidikan Moral." Jurnal Penelitian Agama, Vol. 19 No, 2029.

http:/ / ejournal.iainpurwokerto.ac.id/in dex.php/jpa, diunduh 18 Juni 2021. https:/ / doi.org/10.24090/jpa.v19i2.2018 .pp20-29

Palmquist, S. (2005). Fondasi Psikologi Perkembangan: Menyelami Mimpi, Mencapai Kematangan Diri (Terjemahan). Pustaka Pelajar.

Rahmawati, A. (2018). "Kepribadian Tokoh Kevin dalam Novel Seperti Hujan yang Jatuh ke Bumi Karya Boy Candra: Kajian Psikoanalisis Carl Gustav Jung." Jurnal Bapala, Vol.5, No., 1--18. https://jurnalmahasiswa.unesa.ac.id/in dex.php/bapala/article/view/27889/25 515, diunduh 24 Juni 2020. https:/ / doi.org/10.21107/metalingua.v 5 i1 1.6523

Rokhmansyah, A. (2018). "Struktur Ketaksadaran Kolektif Tokoh Utama dalam Novel The Sweet Sins Karya Rangga Wirianto Putra." Aksara, Vol. 30, $N, 221-236$.

https:/ / doi.org/10.29255/aksara.v30i2.3 21.221-236

Rokhmawan, T. (2019). “Kenapa Kita Harus Percaya Legenda Kiai?" Jurnal AlMakrifat, Vol 4, No, 1--43. https://www.researchgate.net/profile/ Bayu_Firmansyah2/publication/332555 937_Kenapa_Kita_Harus_Percaya_Lege nda_Kiai/links/5cbd83724585156cd7a8 d474/Kenapa-Kita-Harus-PercayaLegenda-Kiai.pdf, diunduh 17 Juli 2020

Saliyo. (2018). “Manfaat Perilaku Spiritual Sufi pada Kesehatan Mental dan Well Being Seseorang." Jurnal Studia Insania, Vol. 6, No, 1--18. https://doi.org/10.18592/jsi.v6i1.2008 